OPEN ACCESS

Edited by: Mingyu Chen,

Sir Run Run Shaw Hospital, China

Reviewed by:

Seyed Alireza Javadinia,

Sabzevar University of Medical

Sciences, Iran

Ming-Yii Huang,

Kaohsiung Medical University

Hospital, Taiwan

*Correspondence:

Kyubo Kim

kyubokim.ro@gmail.com

Hae Jin Park

haejinpark@hanyang.ac.kr

Specialty section: This article was submitted to

Surgical Oncology,

a section of the journal

Frontiers in Oncology

Received: 23 September 2021 Accepted: 21 January 2022

Published: 11 February 2022

Citation:

Lee SJ, Kim K and Park HJ (2022) Meta-Analysis on the Neutrophil-Lymphocyte Ratio in Rectal Cancer Treated With Preoperative Chemoradiotherapy:

Prognostic Value of Pre- and

Post-Chemoradiotherapy Neutrophil-Lymphocyte Ratio.

Front. Oncol. 12:778607. doi: 10.3389/fonc.2022.778607

\section{Meta-Analysis on the Neutrophil- Lymphocyte Ratio in Rectal Cancer Treated With Preoperative Chemoradiotherapy: Prognostic Value of Pre- and Post- Chemoradiotherapy Neutrophil- Lymphocyte Ratio}

\author{
Soo Jin Lee ${ }^{1}$, Kyubo $\mathrm{Kim}^{2 *}$ and Hae Jin Park ${ }^{3 *}$ \\ ${ }^{1}$ Department of Nuclear Medicine, Hanyang University Medical Center, Seoul, South Korea, ${ }^{2}$ Department of Radiation \\ Oncology, Ewha Womans University College of Medicine, Seoul, South Korea, ${ }^{3}$ Department of Radiation Oncology, \\ Hanyang University College of Medicine, Seoul, South Korea
}

Background: To evaluate the prognostic value of neutrophil-lymphocyte ratio (NLR) in rectal cancer patients treated with preoperative chemoradiotherapy (CRT) and curative surgery.

Methods: A comprehensive search of the EMBASE and PubMed databases was performed to screen studies that compared treatment outcomes according to the pre-CRT and/or post-CRT NLR in patients receiving preoperative CRT and curative surgery for locally advanced rectal cancer. Hazard ratios (HRs) for disease-free survival (DFS) and/or overall survival (OS) were extracted, and a random-effects model was used for pooled analysis.

Results: Totally, 22 retrospective studies comprising 6316 patients were included. Preoperative CRT was administered with concurrent chemotherapy (mostly fluoropyrimidine-based regimens). The elevated pre-CRT NLR was significantly associated with an increased risk of recurrence $(H R, 1.54$; 95\% confidence interval $[\mathrm{Cl}]$, 1.31-1.81) and death ( $\mathrm{HR}, 2.14 ; 95 \% \mathrm{Cl}, 1.61-2.84)$. Post-CRT NLR was reported in only 3 of 22 studies, and the correlation was not statistically significant for recurrence (HR, 1.44; 95\% Cl, 0.86-2.41) or death (HR, 2.38; 95\% Cl, 0.94-6.07).

Conclusions: Elevated pre-CRT NRL, but not post-CRT NRL, is associated with inferior DFS and OS. Further studies are needed to confirm the prognostic value of NLR in rectal cancer patients receiving preoperative CRT.

Keywords: rectal cancer, meta-analysis, neutrophil-lymphocyte ratio, radiotherapy, chemoradiotherapy 


\section{INTRODUCTION}

In locally advanced rectal cancer, preoperative chemoradiotherapy (CRT) has been the standard of care since the landmark study by Sauer et al. (1) For those patients treated with preoperative CRT, several prognostic factors based on tumor characteristics have been reported including ypT classification, ypN classification, tumor regression grade, and neoadjuvant rectal score (2).

Moreover, systemic inflammation-related biomarkers are increasingly applied to predict treatment outcomes. Among these, the neutrophil-lymphocyte ratio (NLR) assay is costeffective and easy to perform, and its prognostic value has been reported in many malignancies (3).

Recently, Choi et al. (4) evaluated the prognostic impact of pre-RT NLR using 38 datasets including head and neck cancer, rectal cancer, and lung cancer. Among these, the treatment aim was preoperative in 6 of 38 datasets, and all of them were of rectal cancers. The hazard ratio (HR) of pre-RT elevated NLR for overall survival (OS) was 2.45, which was greater in rectal cancer than other primary tumors. However, only 990 rectal cancer patients were analyzed in their study.

Therefore, we conducted this systematic review and metaanalysis to determine the correlation between NLR and treatment outcomes in patients receiving preoperative CRT followed by curative surgery for locally advanced rectal cancer.

\section{METHODS}

This systematic review was conducted using structured search terms following the Preferred Reporting Items for Systematic Reviews and Meta-Analyses guidelines (Supplementary Table 1)

\section{Search Strategy}

In February 2021, two authors (Lee and Park) performed a comprehensive computer literature search of two databases (EMBASE and PubMed) to identify relevant published studies without a time period limitation. An additional manual search using the reference lists of related literature was also performed. The studies identified from the literature search were evaluated for duplicates; then, full-text articles were independently assessed by two authors (Lee and Park) to determine the eligibility of each article. Studies irrelevant to our research questions were eliminated.

The following search criteria were used: ('neutrophil lymphocyte ratio' OR 'neutrophil-to-lymphocyte ratio' OR 'neutrophil-lymphocyte ratio" OR NLR) AND ('rectal neoplasms' OR 'rectal neoplasm' OR 'rectal tumor' OR 'rectal cancer'). All searches were limited to full-text articles and human studies written in English. All patients and both prospective and retrospective studies were included.

\section{Inclusion and Exclusion Criteria}

Two authors (Kim and Park) independently reviewed the screened studies, and any discrepancies were resolved by discussions. Studies in our meta-analysis were included only if they mentioned all of the following: 1) histologically confirmed rectal cancer; 2) preoperative CRT followed by curative resection,
3) NLR measured before and/or after CRT; 4) association of NLR with OS and/or disease-free survival (DFS); 5) HR with 95\% confidence interval (CI), or sufficient data to estimate HR and standard error (SE). The studies were excluded if the HR and its SE could not be extracted from the reported data. Moreover, studies of poor quality published in journals without an impact factor were excluded by discussion. When the data considered were published in more than one article, only the first related article was included.

\section{Data Extraction}

Two reviewers (Kim and Park) independently extracted data from each article and record them on a standardized form. Any disagreement in data extraction was resolved by discussion. The following data were extracted from each article: (1) first author's name, year of publication, median age of patients, number of included patients, study design (prospective or retrospective), and follow-up periods; (2) detailed information on treatment, TNM stage, and NLR cut-off value; (3) raw data as well as HR for DFS or OS before and after CRT. When the data were presented as a figure, data extraction was performed using Engauge Digitizer software (version 10.4, http:// markummitchell.github.io/engauge-digitizer/). If included studies presented HRs by both univariate and multivariate analysis, the former one was used for pooling data across studies.

\section{Assessment of Risk of Bias and Quality Assessment}

We generated funnel plots to assess possible publication bias. The asymmetricity of plots was tested using trim and fill methods, and the pooled risk estimates were recalculated with the addition of those missing studies.

Quality assessment of the studies was based on the NewcastleOttawa scale (NOS); an NOS score of $\geq 6$ indicated high-quality studies. Consensus was reached by discussion when disparity occurred. After quality assessment, only high-quality studies were included in our analysis (Supplementary Table 2)

\section{Statistical Analysis}

All analyses and corresponding plots were performed using the statistical software R version 3.6.1 (R Foundation for Statistical Computing) (5) using the "meta" (6) and "metaphor" (7) package. A random-effects model was constructed for all included studies to analyze DFS and OS associated with NLR before and after CRT. Heterogeneity was assessed by the likelihood ratio $I^{2}$ index, which is considered high when $>50 \%$. Subgroup analysis was performed to determine whether some individual studies explained heterogeneity and to assess the consistency of the results.

\section{RESULTS}

\section{Study Selection and Characteristics}

A total of 117 studies (57 from EMBASE, 78 from PubMed, and 4 from manual searches) were screened after the removal of duplicates (Figure 1). Based on the titles and abstracts, 29 studies were judged as potentially relevant and evaluated in more detail. After reviewing the full text, 7 studies (8-14) were 
excluded for not meeting the eligibility criteria. The remaining 22 studies (15-36) comprising 6316 rectal cancer patients were included in this meta-analysis. Important characteristics of these studies are presented in Table 1. All studies were retrospective observational studies. Twenty studies reported the association between pre-CRT NLR and treatment outcomes, and 3 studies $(27,31,33)$ reported the association between both preCRT and post-CRT NLR and treatment outcomes. The sample size of individual studies was 48-1527, and the mean age of patients was 51-66 years. Most studies adopted long-course CRT, mostly concurrent with fluoropyrimidine-based regimens. Two-thirds utilized adjuvant chemotherapy, but onethird did not provide information on this. The cut-off value of NLR by various methods was $1.7-5$ for DFS and OS.

\section{Meta-Analysis Results}

The HRs of DFS and OS with pre-CRT NLR were 1.54 (95\% CI, $1.31-1.81)$ and 2.14 (95\% CI, 1.61-2.84), respectively (Figure 2). Substantial heterogeneity was noted $\left(I^{2}=60 \%\right.$ and $78 \%$, respectively). The elevated pre-CRT NLR was strongly associated with worse treatment outcomes in patients with rectal cancer. Funnel tests using the trim and fill methods were conducted for publication bias assessment; Supplementary Figure 1 shows asymmetry, indicating publication bias in both DFS and OS. After the application of the trim and fill methods, the adjusted pooled analysis still presented increased HRs for both DFS and OS (adjusted HR of DFS $=1.31,95 \%$ CI, 1.10-1.55; adjusted HR of OS $=1.36,95 \%$ CI, 0.96-1.93).

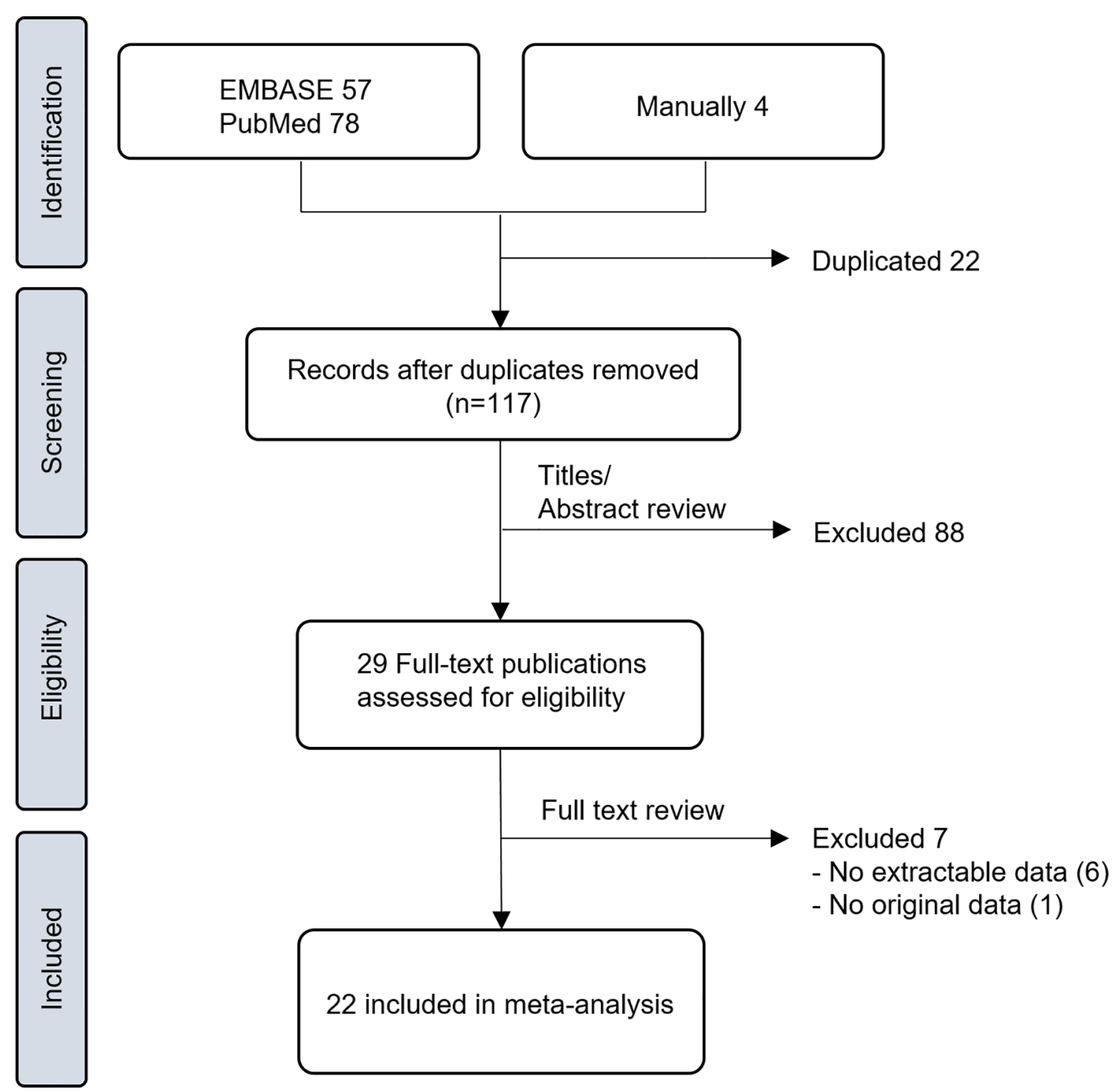

FIGURE 1 | Flow diagram of study selection. 
TABLE 1 | Details of the included studies.

\begin{tabular}{|c|c|c|c|c|c|c|c|c|c|c|c|c|c|}
\hline $\begin{array}{l}\text { First } \\
\text { author }\end{array}$ & $\begin{array}{c}\text { Year of } \\
\text { publication }\end{array}$ & Country & $\begin{array}{l}\text { Number } \\
\text { of } \\
\text { patients }\end{array}$ & $\begin{array}{l}\text { Median } \\
\text { age } \\
\text { (years) }\end{array}$ & $\begin{array}{l}\text { Median } \\
\text { follow-up } \\
\text { (months) }\end{array}$ & $\begin{array}{l}\text { Pre-CRT } \\
\text { stage }\end{array}$ & Treatments, RT & $\begin{array}{c}\text { Treatments, } \\
\text { concurrent CTx }\end{array}$ & $\begin{array}{c}\text { Treatments, } \\
\text { adjuvant CTx }\end{array}$ & $\begin{array}{c}\text { Cut-off } \\
\text { value of } \\
\text { NLR }\end{array}$ & $\begin{array}{l}\text { Cut-off } \\
\text { method }\end{array}$ & Outcome & NOS \\
\hline $\begin{array}{l}\text { Carruthers } \\
\text { R (15) }\end{array}$ & 2012 & UK & 115 & 63.8 & 37.1 & сТ3-4 & $45 \mathrm{~Gy} / 25 \mathrm{fx}$ & 5-FU + folic acid & NA & 5 & NA & DFS, OS & 7 \\
\hline $\begin{array}{l}\text { Toiyama Y } \\
\text { (16) }\end{array}$ & 2013 & Japan & 84 & 64.5 & 56 & I, II, III & $\begin{array}{l}20 \text { Gy/4 fx (57\%), } 45 \\
\text { Gy/25 fx (43\%) }\end{array}$ & $5-F U$ + tegafur/uracil & 5-FU-based & 3 & NA & DFS, OS & 7 \\
\hline $\begin{array}{l}\text { Shen L } \\
\text { (18) }\end{array}$ & 2014 & China & 199 & 55 & 31 & $\|\|$, & $\begin{array}{l}\text { median } 50 \text { Gy, 1.8- } \\
2.0 \mathrm{~Gy} / \mathrm{fx}\end{array}$ & 5-FU-based & $\begin{array}{l}92.5 \% \text {, regimen } \\
\text { NA }\end{array}$ & 2.8 & $\mathrm{ROC}$ analysis & DFS, OS & 7 \\
\hline Kim IY (17) & 2014 & Korea & 102 & NA & 39 & II, III & $50.4 \mathrm{~Gy} / 28 \mathrm{fx}$ & 5-FU + leucovorin & $\begin{array}{l}\text { 5-FU + } \\
\text { leucovorin }\end{array}$ & 3 & NA & DFS, OS & 7 \\
\hline $\begin{array}{l}\text { Nagasaki T } \\
\text { (19) }\end{array}$ & 2015 & Japan & 201 & 61 & 51.2 & $\|\|$, & $\begin{array}{l}45-50 \text { Gy, } 1.8-2.0 \\
\text { Gy/fx }\end{array}$ & 5-FU-based & $\begin{array}{l}45.3 \% \text {, regimen } \\
\text { NA }\end{array}$ & 3 & $\mathrm{ROC}$ analysis & DFS, OS & 7 \\
\hline $\begin{array}{l}\text { Hodek M } \\
\text { (20) }\end{array}$ & 2016 & $\begin{array}{l}\text { Czech } \\
\text { Republic }\end{array}$ & 173 & 62.8 & 35 & $\begin{array}{l}\text { locally } \\
\text { advanced }\end{array}$ & 50.4 Gy/28 fx & $5-\mathrm{FU}$ & $\begin{array}{l}83.4 \% \text {, regimen } \\
\text { NA }\end{array}$ & 2.8 & $\begin{array}{l}\text { log-rank } \\
\text { statistics }\end{array}$ & DFS, OS & 7 \\
\hline $\begin{array}{l}\text { Jung SW } \\
\text { (21) }\end{array}$ & 2017 & Korea & 984 & 59 & 48 & II, III & 50.4-55.4 Gy/28 fx & $\begin{array}{l}\text { 5-FU + leucovorin or } \\
\text { Capcitabine }\end{array}$ & NA & 1.7 & $\mathrm{ROC}$ analysis & DFS & 7 \\
\hline $\begin{array}{l}\text { Zhao J } \\
\text { (23) }\end{array}$ & 2017 & China & 100 & 60.5 & 45.5 & II, III & $50-55$ Gy/25 fx & Capcitabine-based & NA & 2.25 & $\mathrm{ROC}$ analysis & OS & 7 \\
\hline $\begin{array}{l}\text { Shen J } \\
\text { (22) }\end{array}$ & 2017 & China & 202 & 51 & 45 & II, III & $\begin{array}{l}\text { 45-55 Gy, long- } \\
\text { course }\end{array}$ & $\begin{array}{l}\text { 5-FU-based (FOLFIRI } \\
\text { or FOLFOX) }\end{array}$ & $\begin{array}{l}53.5 \% \text {, regimen } \\
\text { NA }\end{array}$ & 3 & $\mathrm{ROC}$ analysis & DFS, OS & 7 \\
\hline $\begin{array}{l}\text { Vallard A } \\
\text { (24) }\end{array}$ & 2018 & France & 257 & 66 & 46.1 & I, II, III & $\begin{array}{l}\text { median EQD2 } 49.2 \\
\text { Gy, HypoFx } 7.8 \% \\
\text { included }\end{array}$ & $\begin{array}{l}\text { 5-FU or FOLFOX } \\
\text { (4.6\% not done) }\end{array}$ & $\begin{array}{l}38.8 \%, \text { FOLFOX } \\
\text { or } 5-F U\end{array}$ & 2.8 & $\begin{array}{l}\text { log-rank } \\
\text { statistics }\end{array}$ & DFS, OS & 7 \\
\hline $\begin{array}{l}\text { Ward WH } \\
\text { (25) }\end{array}$ & 2018 & USA & 146 & 58.6 & NA & II, III & $\begin{array}{l}\text { median } 50.4 \text { Gy, } \\
\text { 1.8-2.0 Gy/fx }\end{array}$ & $\begin{array}{l}\text { 5-FU or Capcitabine } \\
\text { or multi-agent }\end{array}$ & NA & 4.47 & $\begin{array}{l}\text { maximally } \\
\text { selected rank } \\
\text { statistics }\end{array}$ & DFS, OS & 6 \\
\hline $\begin{array}{l}\text { Kim TG } \\
\text { (29) }\end{array}$ & 2019 & Korea & 176 & 57 & 75 & II, III & $\begin{array}{l}44-45 \text { Gy, } 1.8-2.0 \\
\text { Gy/fx }\end{array}$ & 5-FU or Capcitabine & $\begin{array}{l}100 \% \text {, regimen } \\
\text { NA }\end{array}$ & 2 & $\mathrm{ROC}$ analysis & DFS, OS & 8 \\
\hline $\begin{array}{l}\text { Dudani S } \\
\text { (28) }\end{array}$ & 2019 & Canada & 1527 & 62 & 71 & II, III & $\begin{array}{l}\text { median } 50 \text { Gy, long- } \\
\text { course }\end{array}$ & 5-FU or Capcitabine & $\begin{array}{l}83 \%, 5-\mathrm{FU}- \\
\text { based }\end{array}$ & 4 & NA & DFS, OS & 8 \\
\hline $\begin{array}{l}\text { Braun LH } \\
\text { (26) }\end{array}$ & 2019 & Germany & 220 & 65.5 & 67 & II, III & long-course & 5-FU-based & $\begin{array}{l}55.5 \% \text {, regimen } \\
\text { NA }\end{array}$ & 4.06 & $\mathrm{ROC}$ analysis & DFS & 8 \\
\hline $\begin{array}{l}\text { Cha YJ } \\
(27)\end{array}$ & 2019 & Korea & 131 & 59 & 73.3 & II, III & mean 50.4 Gy/28 fx & 5-FU or Capcitabine & $\begin{array}{l}85.5 \% \text {, mainly } 5 \text { - } \\
\text { FU or } \\
\text { Capcitabine }\end{array}$ & 3 & NA & DFS, OS & 8 \\
\hline $\begin{array}{l}\text { Zhang X } \\
\text { (30) }\end{array}$ & 2019 & China & 76 & $\begin{array}{l}\text { NA } \\
(74 \% \\
<60)\end{array}$ & 23 & II, III & $\begin{array}{l}50 \mathrm{~Gy} / 25 \mathrm{fx} \text { or } \\
25 \mathrm{~Gy} / 5 \mathrm{fx}\end{array}$ & $\begin{array}{l}\text { 5-FU-based for long- } \\
\text { course RT }\end{array}$ & NA & 2 & $\begin{array}{l}\text { Cutoff Finder } \\
\text { software }\end{array}$ & OS & 6 \\
\hline Sun Y (34) & 2020 & China & 317 & 55.5 & 54 & $\|\|$, & 50.4 Gy/28 fx & $\begin{array}{l}\text { capecitabine + } \\
\text { oxaliplatin or FOLFOX }\end{array}$ & $\begin{array}{l}\text { capecitabine + } \\
\text { oxaliplatin or } \\
\text { FOLFOX }\end{array}$ & 2.9 & $\mathrm{X}$-tile analysis & DFS, OS & 7 \\
\hline $\mathrm{KeT}(32)$ & 2020 & Taiwan & 184 & 63.17 & 72.7 & I, II, III & $45-50 \mathrm{~Gy} / 25-28 \mathrm{fx}$ & 5-FU-based & $\begin{array}{l}100 \%, \text { FOLFOX } \\
\text { or } 5 \text {-FU/ } \\
\text { leucovorin or } \\
\text { capcitabine }\end{array}$ & 3.5 & mean value & DFS, OS & 8 \\
\hline $\begin{array}{l}\text { Lee JH } \\
\text { (33) }\end{array}$ & 2020 & Korea & 549 & 61 & NA & I, II, III & $\begin{array}{l}\text { median } 50.4 \text { Gy, } \\
1.8-2.0 \mathrm{~Gy} / \mathrm{fx}\end{array}$ & 5-FU or Capcitabine & NA & 2 & median value & DFS, OS & 6 \\
\hline $\begin{array}{l}\text { Zhang Y } \\
\text { (35) }\end{array}$ & 2020 & China & 472 & 56 & NA & $\|\|$, & $50.4 \mathrm{~Gy} / 28 \mathrm{fx}$ & done, regimen NA & $\begin{array}{l}\text { done, regimen } \\
\text { NA }\end{array}$ & 2.3 & $\mathrm{X}$-tile analysis & DFS, OS & 6 \\
\hline $\begin{array}{l}\text { Ishikawa D } \\
\text { (31) }\end{array}$ & 2020 & Japan & 48 & 66 & $\begin{array}{c}36 \text { for DFS, } \\
60 \text { for OS }\end{array}$ & I, II, III & $40 \mathrm{~Gy} / 20 \mathrm{fx}$ & $\begin{array}{l}\text { tegafur-gimeracil- } \\
\text { oteracil or tegafur- } \\
\text { uracil or } 5 \text {-FU }\end{array}$ & NA & 2.45 & median value & DFS, OS & 6 \\
\hline $\begin{array}{l}\text { Ergen SA } \\
\text { (36) }\end{array}$ & 2021 & Turkey & 53 & 55 & 43 & II, III & $50.4 \mathrm{~Gy} / 28 \mathrm{fx}$ & Capcitabine & $\begin{array}{l}43.4 \% \text {, regimen } \\
\text { NA }\end{array}$ & 2.49 & $\mathrm{ROC}$ analysis & OS & 6 \\
\hline
\end{tabular}

CRT, chemoradiotherapy; RT, radiotherapy; CTx, chemotherapy; NLR, neutrophil-lymphocyte ratio; NOS, Newcastle-Ottawa Quality Assessment Scale; NA, not available; DFS, diseasefree survival; OS, overall survival; ROC, receiver operating characteristic.

Only 3 studies $(27,31,33)$ reported the post-CRT NLR as well. Figure 3 shows that elevated post-CRT NLR is not associated with DFS or OS. The HRs of DFS and OS were 1.44 (95\% CI, 0.86-2.41, $\left.I^{2}=41 \%\right)$ and $2.38\left(95 \% \mathrm{CI}, 0.94-6.07, I^{2}=45 \%\right)$, respectively.

\section{DISCUSSION}

In this meta-analysis, elevated pre-CRT NLR was associated with 1.5- and 2-fold higher risks of relapse and death, respectively, in 
A

\section{Study}

Univariate analysis

Carruthers 2012

Toiyama 2013

Shen 2014

Kim 2014

Nagasaki 2015

Hodek 2016

Vallard 2017

Shen 2017

Ward 2018

Dunani 2019

Braun 2019

Cha 2019

Sun 2020

Ke 2020

Lee 2020

Zhang 2020

Ishikawa 2020

Random effects model

Heterogeneity: $I^{2}=62 \%, \tau^{2}=0.0572, p<0.01$

Multivariate analysis

Jung 2017

Kim 2019

Random effects model

Heterogeneity: $I^{2}=7 \%, \tau^{2}=0.0109, p=0.30$

Random effects model

Heterogeneity: $I^{2}=60 \%, \tau^{2}=0.0567, p<0.01$
$0.28 \quad 0.4210$

TE seTE

Hazard Ratio

$1.03 \quad 0.3220$

$0.62 \quad 0.4760$

0.510 .2410

1.280 .4540

0.070 .3590

$0.14 \quad 0.0940$

$0.83 \quad 0.2710$

$\begin{array}{rl}-0.15 & 0.2430\end{array}$

1.340 .5690

$0.22 \quad 0.1080$

0.810 .3900

0.700 .4330

0.160 .0800

0.670 .1890

0.140 .1630

0.730 .1960

$-0.34 \quad 0.5770$

0.830 .3250

50

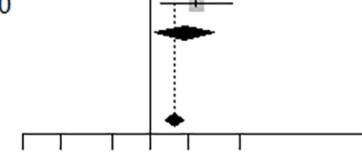

$\begin{array}{lllll}0.10 .2 & 0.5 & 1 & 2 & 5\end{array}$

lower NLR - higher NLR
HR $\quad 95 \%-\mathrm{Cl}$ Weight

$2.80[1.49 ; 5.27] \quad 42 \%$

$1.86[0.73 ; 4.73] \quad 2.4 \%$

$1.66 \quad[1.04 ; 2.67] \quad 5.9 \%$

$3.60[1.48 ; 8.77] \quad 2.6 \%$

$1.07[0.53 ; 2.17] \quad 3.7 \%$

$1.15 \quad[0.96 ; 1.38] \quad 10.3 \%$

$2.29[1.35 ; 3.90] \quad 5.2 \%$

$0.86[0.54 ; 1.39] \quad 5.9 \%$

$3.80[1.25 ; 11.59] \quad 1.8 \%$

$1.24[1.00 ; 1.53] \quad 9.9 \%$

$2.25[1.05 ; 4.83] \quad 3.2 \%$

$2.01[0.86 ; 4.70] \quad 2.8 \%$

$1.17[1.00 ; 1.37] \quad 10.7 \%$

$1.96[1.35 ; 2.83] \quad 7.3 \%$

$1.15[0.84 ; 1.59] \quad 8.1 \%$

2.08 [1.41; 3.05] $7.1 \%$

$0.71[0.23 ; 2.21] \quad 1.7 \%$

$1.52[1.28 ; 1.80] \quad 92.9 \%$

$1.32[0.58 ; 3.01] \quad 2.9 \%$

$2.29[1.21 ; 4.33] \quad 4.2 \%$

$1.85[1.10 ; 3.14] \quad 7.1 \%$

$[1.31 ; 1.81] 100.0 \%$

50

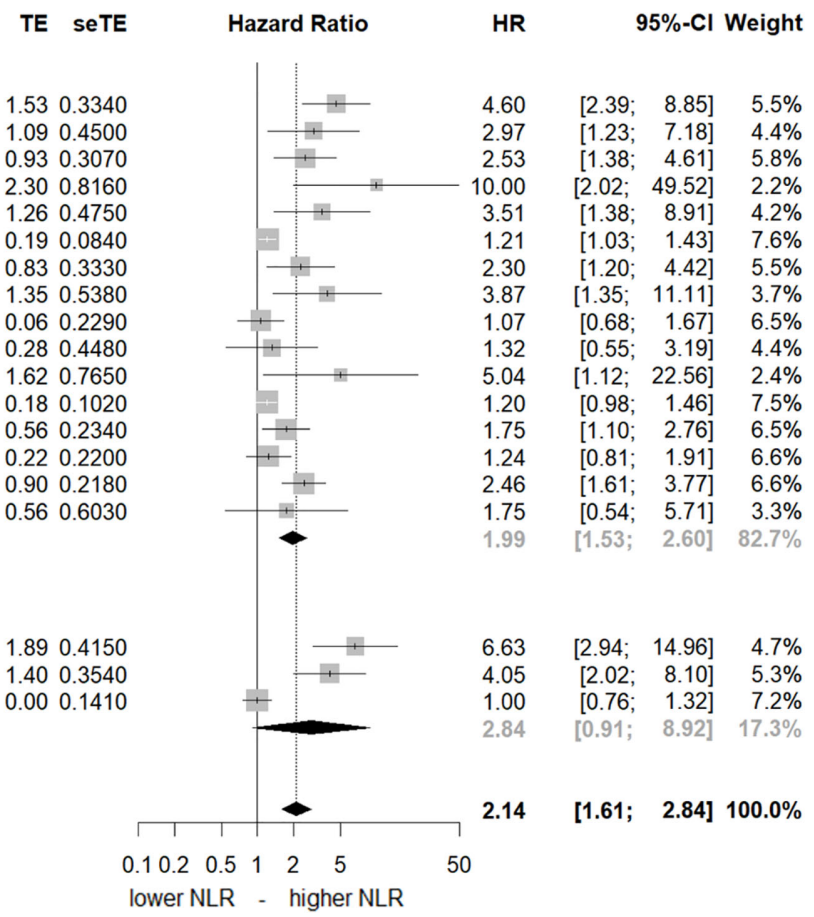

FIGURE 2 | Forest plot of hazard ratios (HR) for an elevated neutrophil-lymphocyte ratio (NLR) before chemoradiotherapy. (A) disease-free-survival and (B) overall survival. The squares represent HR for each study and their size represents the weight of the study in the meta-analysis. The horizontal lines crossing the squares represent the $95 \%$ confidence intervals $(\mathrm{Cl})$. 


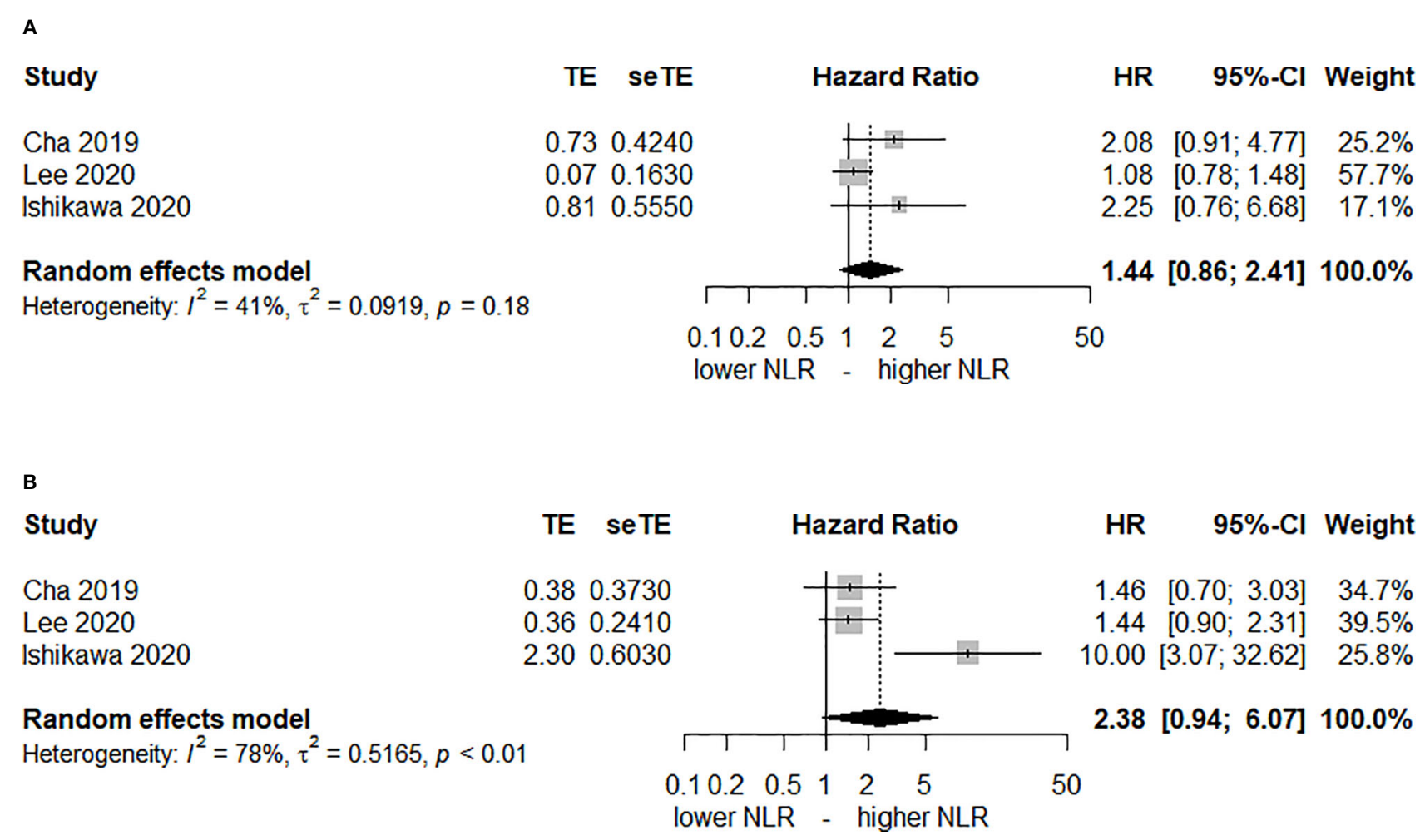

FIGURE 3 | Forest plot of hazard ratios (HR) for an elevated neutrophil-lymphocyte ratio (NLR) after chemoradiotherapy. (A) disease-free-survival and (B) overall survival.

patients treated with preoperative CRT and curative surgery for locally advanced rectal cancer.

An elevated NLR could result from either neutrophilia or lymphopenia, both of which are reported to be associated with poor prognosis in many malignancies (37). Neutrophils are known to release inflammatory cytokines such as nuclear factor kappa B as well as reactive oxygen and nitrogen species, and they can promote angiogenesis and tumor growth. Neutrophilia can predict inferior survival outcomes in rectal, anal, and cervical cancers (38-40). Lymphopenia inversely correlates with the number of tumor-infiltrating lymphocytes, and therefore, it might suggest impaired antitumoral immunity, which in turn could promote tumor progression. Given that lymphocytes are highly radiosensitive, and treatment-related lymphopenia is often reported, the utility of using post-RT lymphopenia as a prognostic factor in various tumors has been suggested (41). Although not as often as post-RT lymphopenia, pre-RT lymphopenia is also reported to correlate with treatment outcomes. Li et al. (42) observed that pre-RT lymphopenia is associated with poorer survival after stereotactic radiosurgery in lung cancer patients with brain metastases. Although the response to preoperative CRT was not analyzed in our study, Hodek et al. (20) and Kim et al. (17) noted that the NLR level is correlated with pathologic tumor response as well as survival. Choi et al. (4) suggested that hypoxia, which is well known to decrease response to radiation therapy, could be driving this relationship. They speculated that tumor growth and necrosis create a hypoxic environment, which triggers an inflammatory response by modulating cytokine expression.

Recently, Hamid et al. (43) conducted a meta-analysis regarding the prognostic impact of NLR in rectal cancer patients undergoing curative resection and noted that pretreatment NLR is significantly correlated with DFS and OS. However, they analyzed mixed populations treated with surgery alone or preoperative CRT followed by surgery. Our study included only patients receiving preoperative CRT before surgery, and pre-CRT NLR significantly correlated with survival. Meanwhile, a Canadian multicenter study (28) with the largest effect size reported that an elevated pre-CRT NLR level is not associated with OS on both univariate and multivariate analyses. When the patient and tumor characteristics were compared according to the pre-CRT NLR level, a higher pre-CRT NLR was associated with older age, poor performance status, and lower hemoglobin level, of which age and performance status were significant prognostic factors affecting OS on multivariate analysis. Therefore, further studies are needed to confirm the prognostic value of NLR after adjusting for potential confounding factors.

Total neoadjuvant treatment (TNT) is an emerging issue in the management of locally advanced rectal cancer, and early results from randomized controlled trials are promising $(44,45)$. However, the impact of NLR in the setting of TNT has not yet been established. Recently, Roy et al. (46) noted that baseline NLR level is associated with DFS and OS on univariate analysis 
but not on multivariate analysis in patients receiving shortcourse RT (25 Gy in 5 fractions) followed by chemotherapy and delayed surgery. It was not clear whether the lack of significant correlation between NLR and the outcomes in the aforementioned study was due to the hypofractionated RT or the treatment sequencing. However, in the TNT setting employing upfront CRT, post-CRT NLR might give additional information regarding the best candidate requiring post-CRT chemotherapy prior to surgery. Treatment-related lymphopenia is reported to be common in rectal cancer patients undergoing neoadjuvant CRT, and its association with a poor prognosis has also been observed $(47,48)$. In the present study, only 3 articles reported the impact of post-CRT NLR, but the correlation was not statistically significant, and only unadjusted HRs were reported. Further research is warranted for estimating the implication of post-CRT NLR in the context of TNT. Moreover, such post-CRT biomarkers might facilitate the selection of potential candidates of "watch-and-wait" strategy.

There are some shortcomings in this study. First, there were only 3 studies to report adjusted HRs for pre-CRT NLR. There could be an underlying correlation between pre-CRT NLR and baseline patient and/or tumor characteristics, and therefore, the impact of NLR might disappear on multivariate analysis after adjusting for potential covariates. Second, patient-, tumor-, and treatment-related heterogeneities, as well as different cut-offs for the NLR level applied in the included studies, could have influenced the results. Third, the inclusion of different treatments might affect the results of our study: 3 studies employed short-course radiotherapy in part and another 3 studies also employed oxaliplatin-based regimen as the concomitant chemotherapy in part. Lastly, we did not analyze the effect of pre- and post-CRT NLR on pathologic tumor response because of the lack of reported HRs in included studies. Another meta-analysis focused on this important topic is warranted in the future.

\section{REFERENCES}

1. Sauer R, Becker H, Hohenberger W, Rodel C, Wittekind C, Fietkau R, et al. Preoperative Versus Postoperative Chemoradiotherapy for Rectal Cancer. N Engl J Med (2004) 351(17):1731-40. doi: 10.1056/NEJMoa040694

2. Rodel C, Martus P, Papadoupolos T, Fuzesi L, Klimpfinger M, Fietkau R, et al. Prognostic Significance of Tumor Regression After Preoperative Chemoradiotherapy for Rectal Cancer. J Clin Oncol (2005) 23(34):8688-96. doi: 10.1200/JCO.2005.02.1329

3. George TJJr., Allegra CJ, Yothers G. Neoadjuvant Rectal (NAR) Score: A New Surrogate Endpoint in Rectal Cancer Clinical Trials. Curr Colorectal Cancer Rep (2015) 11(5):275-80. doi: 10.1007/s11888-015-0285-2

4. Choi N, Kim JH, Chie EK, Gim J, Kang HC. A Meta-Analysis of the Impact of Neutrophil-to-Lymphocyte Ratio on Treatment Outcomes After Radiotherapy for Solid Tumors. Med (Baltimore) (2019) 98(18):e15369. doi: 10.1097/MD.0000000000015369

5. Team RC. A Language and Environment for Statistical Computing. Vienna, Austria: R Foundation for Statistical Computing (2019). Available at: https:// R-project.org.

6. Balduzzi S, Rucker G, Schwarzer G. How to Perform a Meta-Analysis With R: A Practical Tutorial. Evid Based Ment Health (2019) 22(4):153-60. doi: 10.1136/ebmental-2019-300117

7. Viechtbauer W. Conducting Meta-Analyses in R With the Metafor Package. J Stat Softw (2010) 36(3):1-48. doi: 10.18637/jss.v036.i03
In conclusion, elevated pre-CRT NLR is associated with inferior DFS and OS in rectal cancer, but post-CRT NRL is not. Further studies are needed to confirm the prognostic value of NLR in rectal cancer patients receiving preoperative CRT.

\section{DATA AVAILABILITY STATEMENT}

The original contributions presented in the study are included in the article/Supplementary Material. Further inquiries can be directed to the corresponding authors.

\section{AUTHOR CONTRIBUTIONS}

KK and HP designed the study and collected the data. SL performed the statistical analysis of the collected data. All three authors wrote the manuscript. All authors contributed to the article and approved the submitted version.

\section{FUNDING}

This work was carried out with the support of the research fund of Hanyang University (HY-2020).

\section{SUPPLEMENTARY MATERIAL}

The Supplementary Material for this article can be found online at: https://www.frontiersin.org/articles/10.3389/fonc.2022. 778607/full\#supplementary-material

Supplementary Figure 1 | Funnel plots with trim-and-fill. (A) disease-freesurvival and (B) overall survival before chemoradiotherapy.

8. Dou X, Wang RB, Yan HJ, Jiang SM, Meng XJ, Zhu KL, et al. Circulating Lymphocytes as Predictors of Sensitivity to Preoperative Chemoradiotherapy in Rectal Cancer Cases. Asian Pac J Cancer Prev (2013) 14(6):3881-5. doi: 10.7314/apjcp.2013.14.6.3881

9. Krauthamer M, Rouvinov K, Ariad S, Man S, Walfish S, Pinsk I, et al. A Study of Inflammation-Based Predictors of Tumor Response to Neoadjuvant Chemoradiotherapy for Locally Advanced Rectal Cancer. Oncology (2013) 85(1):27-32. doi: 10.1159/000348385

10. Lee IH, Hwang S, Lee SJ, Kang BW, Baek D, Kim HJ, et al. Systemic Inflammatory Response After Preoperative Chemoradiotherapy Can Affect Oncologic Outcomes in Locally Advanced Rectal Cancer. Anticancer Res (2017) 37(3):1459-65. doi: 10.21873/anticanres.11470

11. Lino-Silva LS, Salcedo-Hernandez RA, Ruiz-Garcia EB, Garcia-Perez L, Herrera-Gomez A. Pre-Operative Neutrophils/Lymphocyte Ratio in Rectal Cancer Patients With Preoperative Chemoradiotherapy. Med Arch (2016) 70 (4):256-60. doi: 10.5455/medarh.2016.70.256-260

12. Portale G, Cavallin F, Valdegamberi A, Frigo F, Fiscon V. Platelet-ToLymphocyte Ratio and Neutrophil-To-Lymphocyte Ratio Are Not Prognostic Biomarkers in Rectal Cancer Patients With Curative Resection. J Gastrointest Surg (2018) 22(9):1611-8. doi: 10.1007/s11605018-3781-2

13. Runau F, Collins A, Fenech GA, Ford E, Dimitriou N, Chaudhri S, et al. A Single Institution's Long-Term Follow-Up of Patients With Pathological Complete Response in Locally Advanced Rectal Adenocarcinoma Following 
Neoadjuvant Chemoradiotherapy. Int J Colorectal Dis (2017) 32(3):341-8. doi: 10.1007/s00384-016-2712-5

14. Sung S, Son SH, Park EY, Kay CS. Prognosis of Locally Advanced Rectal Cancer Can Be Predicted More Accurately Using Pre- and PostChemoradiotherapy Neutrophil-Lymphocyte Ratios in Patients Who Received Preoperative Chemoradiotherapy. PloS One (2017) 12(3): e0173955. doi: 10.1371/journal.pone.0173955

15. Carruthers R, Tho LM, Brown J, Kakumanu S, McCartney E, McDonald AC. Systemic Inflammatory Response Is a Predictor of Outcome in Patients Undergoing Preoperative Chemoradiation for Locally Advanced Rectal Cancer. Colorectal Dis (2012) 14(10):e701-7. doi: 10.1111/j.14631318.2012.03147.x

16. Toiyama Y, Inoue Y, Saigusa S, Kawamura M, Kawamoto A, Okugawa Y, et al. C-Reactive Protein as Predictor of Recurrence in Patients With Rectal Cancer Undergoing Chemoradiotherapy Followed by Surgery. Anticancer Res (2013) 33(11):5065-74.

17. Kim IY, You SH, Kim YW. Neutrophil-Lymphocyte Ratio Predicts Pathologic Tumor Response and Survival After Preoperative Chemoradiation for Rectal Cancer. BMC Surg (2014) 14:94. doi: 10.1186/1471-2482-14-94

18. Shen L, Zhang H, Liang L, Li G, Fan M, Wu Y, et al. Baseline NeutrophilLymphocyte Ratio $(>/=2.8)$ as a Prognostic Factor for Patients With Locally Advanced Rectal Cancer Undergoing Neoadjuvant Chemoradiation. Radiat Oncol (2014) 9:295. doi: 10.1186/s13014-014-0295-2

19. Nagasaki T, Akiyoshi T, Fujimoto Y, Konishi T, Nagayama S, Fukunaga Y, et al. Prognostic Impact of Neutrophil-To-Lymphocyte Ratio in Patients With Advanced Low Rectal Cancer Treated With Preoperative Chemoradiotherapy. Dig Surg (2015) 32(6):496-503. doi: 10.1159/000441396

20. Hodek M, Sirak I, Ferko A, Orhalmi J, Hovorkova E, Hadzi Nikolov D, et al. Neoadjuvant Chemoradiotherapy of Rectal Carcinoma: Baseline Hematologic Parameters Influencing Outcomes. Strahlenther Onkol (2016) 192(9):632-40. doi: 10.1007/s00066-016-0988-6

21. Jung SW, Park IJ, Oh SH, Yeom SS, Lee JL, Yoon YS, et al. Association of Immunologic Markers From Complete Blood Counts With the Response to Preoperative Chemoradiotherapy and Prognosis in Locally Advanced Rectal Cancer. Oncotarget (2017) 8(35):59757-65. doi: 10.18632/oncotarget.15760

22. Shen J, Zhu Y, Wu W, Zhang L, Ju H, Fan Y, et al. Prognostic Role of Neutrophil-To-Lymphocyte Ratio in Locally Advanced Rectal Cancer Treated With Neoadjuvant Chemoradiotherapy. Med Sci Monit (2017) 23:315-24. doi: $10.12659 / \mathrm{msm} .902752$

23. Zhao J, Xu J, Zhang R. Clinical and Prognostic Significance of Pathological and Inflammatory Markers in Mucinous Rectal Cancer Patients Receiving Neoadjuvant Chemoradiotherapy and Curative Surgery. Med Sci Monit (2017) 23:4826-33. doi: 10.12659/msm.904116

24. Vallard A, Garcia MA, Espenel S, Diao P, Vial N, Guy JB, et al. Outcomes Prediction in Pre-Operative Radiation Therapy Locally Advanced Rectal Cancer: Leucocyte Assessment as Immune Biomarker. Int J Radiat Oncol (2018) 102(3):E21-E. doi: 10.1016/j.ijrobp.2018.07.239

25. Ward WH, Goel N, Ruth KJ, Esposito AC, Lambreton F, Sigurdson ER, et al. Predictive Value of Leukocyte- and Platelet-Derived Ratios in Rectal Adenocarcinoma. J Surg Res (2018) 232:275-82. doi: 10.1016/j.jss.2018.06.060

26. Braun LH, Baumann D, Zwirner K, Eipper E, Hauth F, Peter A, et al. Neutrophil-To-Lymphocyte Ratio in Rectal Cancer-Novel Biomarker of Tumor Immunogenicity During Radiotherapy or Confounding Variable? Int J Mol Sci (2019) 20(10):2448. doi: 10.3390/ijms20102448

27. Cha YJ, Park EJ, Baik SH, Lee KY, Kang J. Prognostic Impact of Persistent Lower Neutrophil-to-Lymphocyte Ratio During Preoperative Chemoradiotherapy in Locally Advanced Rectal Cancer Patients: A Propensity Score Matching Analysis. PloS One (2019) 14(3):e0214415. doi: 10.1371 /journal.pone. 0214415

28. Dudani S, Marginean H, Tang PA, Monzon JG, Raissouni S, Asmis TR, et al. Neutrophil-To-Lymphocyte and Platelet-to-Lymphocyte Ratios as Predictive and Prognostic Markers in Patients With Locally Advanced Rectal Cancer Treated With Neoadjuvant Chemoradiation. BMC Cancer (2019) 19(1):664. doi: 10.1186/s12885-019-5892-x

29. Kim TG, Park W, Kim H, Choi DH, Park HC, Kim SH, et al. Baseline Neutrophil-Lymphocyte Ratio and Platelet-Lymphocyte Ratio in Rectal Cancer Patients Following Neoadjuvant Chemoradiotherapy. Tumori (2019) 105(5):434-40. doi: 10.1177/0300891618792476
30. Zhang X, Li J, Peng Q, Huang Y, Tang L, Zhuang Q, et al. Association of Markers of Systemic and Local Inflammation With Prognosis of Patients With Rectal Cancer Who Received Neoadjuvant Radiotherapy. Cancer Manag Res (2019) 11:191-9. doi: 10.2147/CMAR.S187559

31. Ishikawa D, Nishi M, Takasu C, Kashihara H, Tokunaga T, Higashijima J, et al. The Role of Neutrophil-To-Lymphocyte Ratio on the Effect of CRT for Patients With Rectal Cancer. In Vivo (2020) 34(2):863-8. doi: 10.21873/ invivo. 11850

32. Ke TM, Lin LC, Huang CC, Chien YW, Ting WC, Yang CC. High Neutrophilto-Lymphocyte Ratio and Platelet-to-Lymphocyte Ratio Predict Poor Survival in Rectal Cancer Patients Receiving Neoadjuvant Concurrent Chemoradiotherapy. Med (Baltimore) (2020) 99(17):e19877. doi: 10.1097/ MD. 0000000000019877

33. Lee JH, Kang BH, Song C, Kang SB, Lee HS, Lee KW, et al. Microsatellite Instability Correlated Inflammatory Markers and Their Prognostic Value in the Rectal Cancer Following Neoadjuvant Chemoradiotherapy: A Hypothesis-Generating Study. In Vivo (2020) 34(4):2119-26. doi: 10.21873 /invivo.12017

34. Sun Y, Zhang Y, Huang Z, Lin H, Lu X, Huang Y, et al. Combination of Preoperative Plasma Fibrinogen and Neutrophil-To-Lymphocyte Ratio (the F-NLR Score) as a Prognostic Marker of Locally Advanced Rectal Cancer Following Preoperative Chemoradiotherapy. World J Surg (2020) 44(6):197584. doi: $10.1007 / \mathrm{s} 00268-020-05407-3$

35. Zhang Y, Liu X, Xu M, Chen K, Li S, Guan G. Prognostic Value of Pretreatment Systemic Inflammatory Markers in Patients With Locally Advanced Rectal Cancer Following Neoadjuvant Chemoradiotherapy. Sci Rep (2020) 10(1):8017. doi: 10.1038/s41598-020-64684-z

36. Ergen SA, Barlas C, Yildirim C, Oksuz DC. Prognostic Role of Peripheral Neutrophil-Lymphocyte Ratio (NLR) and Platelet-Lymphocyte Ratio (PLR) in Patients With Rectal Cancer Undergoing Neoadjuvant Chemoradiotherapy. J Gastrointest Cancer (2021) [Epub ahead of print]. doi: 10.1007/s12029-020-00578-7

37. Takeshima T, Pop LM, Laine A, Iyengar P, Vitetta ES, Hannan R. Key Role for Neutrophils in Radiation-Induced Antitumor Immune Responses: Potentiation With G-CSF. Proc Natl Acad Sci USA (2016) 113(40):11300-5. doi: $10.1073 /$ pnas. 1613187113

38. Diefenhardt M, Hofheinz RD, Martin D, Beissbarth T, Arnold D, Hartmann A, et al. Leukocytosis and Neutrophilia as Independent Prognostic Immunological Biomarkers for Clinical Outcome in the CAO/ARO/AIO-04 Randomized Phase 3 Rectal Cancer Trial. Int J Cancer (2019) 145(8):2282-91. doi: $10.1002 / \mathrm{ijc} .32274$

39. Mabuchi S, Matsumoto Y, Isohashi F, Yoshioka Y, Ohashi H, Morii E, et al. Pretreatment Leukocytosis Is an Indicator of Poor Prognosis in Patients With Cervical Cancer. Gynecol Oncol (2011) 122(1):25-32. doi: 10.1016/ j.ygyno.2011.03.037

40. Schernberg A, Escande A, Rivin Del Campo E, Ducreux M, Nguyen F, Goere D, et al. Leukocytosis and Neutrophilia Predicts Outcome in Anal Cancer. Radiother Oncol (2017) 122(1):137-45. doi: 10.1016/j.radonc.2016.12.009

41. Venkatesulu BP, Mallick S, Lin SH, Krishnan S. A Systematic Review of the Influence of Radiation-Induced Lymphopenia on Survival Outcomes in Solid Tumors. Crit Rev Oncol Hematol (2018) 123:42-51. doi: 10.1016/ j.critrevonc.2018.01.003

42. Li YD, Lamano JB, Kaur G, Lamano JB, Veliceasa D, Biyashev D, et al. Lymphopenia Predicts Response to Stereotactic Radiosurgery in Lung Cancer Patients With Brain Metastases. J Neurooncol (2019) 143(2):337-47. doi: 10.1007/s11060-019-03169-0

43. Hamid HKS, Davis GN, Trejo-Avila M, Igwe PO, Garcia-Marin A. Prognostic and Predictive Value of Neutrophil-to-Lymphocyte Ratio After Curative Rectal Cancer Resection: A Systematic Review and Meta-Analysis. Surg Oncol (2021) 37:101556. doi: 10.1016/j.suronc.2021.101556

44. Bahadoer RR, Dijkstra EA, van Etten B, Marijnen CAM, Putter H, Kranenbarg EM, et al. Short-Course Radiotherapy Followed by Chemotherapy Before Total Mesorectal Excision (TME) Versus Preoperative Chemoradiotherapy, TME, and Optional Adjuvant Chemotherapy in Locally Advanced Rectal Cancer (RAPIDO): A Randomised, Open-Label, Phase 3 Trial. Lancet Oncol (2021) 22(1):29-42. doi: 10.1016/S1470-2045(20)30555-6

45. Conroy T, Bosset JF, Etienne PL, Rio E, Francois E, Mesgouez-Nebout N, et al. Neoadjuvant Chemotherapy With FOLFIRINOX and Preoperative 
Chemoradiotherapy for Patients With Locally Advanced Rectal Cancer (UNICANCER-PRODIGE 23): A Multicentre, Randomised, Open-Label, Phase 3 Trial. Lancet Oncol (2021) 22(5):702-15. doi: 10.1016/S1470-2045(21)00079-6

46. Roy A, Chin R, Chapman J, Bauer P, Mahkdoom B, Hunt S, et al. Baseline Lymphocyte Counts Do Not Predict Oncologic Outcomes and Survival in Patients Receiving Short Course Total Neoadjuvant Therapy for Rectal Cancer. Int J Radiat Oncol Biol Phys (2020) 108(Suppl):e636-e. doi: 10.1016/j.ijrobp.2020.07.1916

47. Campian JL, Ye X, Sarai G, Herman J, Grossman SA. Severe TreatmentRelated Lymphopenia in Patients With Newly Diagnosed Rectal Cancer. Cancer Invest (2018) 36(6):356-61. doi: 10.1080/07357907.2018.1499028

48. Xu H, You G, Zhang M, Song T, Zhang H, Yang J, et al. Association of PreSurgery to Pre-Radiotherapy Lymphocyte Counts Ratio With Disease-Free Survival in Rectal Cancer Patients Receiving Neoadjuvant Concurrent Chemoradiotherapy. World J Surg Oncol (2019) 17(1):199. doi: 10.1186/ s12957-019-1747-9
Conflict of Interest: The authors declare that the research was conducted in the absence of any commercial or financial relationships that could be construed as a potential conflict of interest.

Publisher's Note: All claims expressed in this article are solely those of the authors and do not necessarily represent those of their affiliated organizations, or those of the publisher, the editors and the reviewers. Any product that may be evaluated in this article, or claim that may be made by its manufacturer, is not guaranteed or endorsed by the publisher.

Copyright (C) 2022 Lee, Kim and Park. This is an open-access article distributed under the terms of the Creative Commons Attribution License (CC BY). The use, distribution or reproduction in other forums is permitted, provided the original author(s) and the copyright owner(s) are credited and that the original publication in this journal is cited, in accordance with accepted academic practice. No use, distribution or reproduction is permitted which does not comply with these terms. 